\title{
Nonplanar Tub-Shaped Benzocyclooctatetraenes via Halogen- Radical Ring Opening of Dihydrobiphenylenes
}

\author{
Jesús Bello-García, Damián Padín, Jesús A. Varela, and Carlos Saá* \\ Cite This: Org. Lett. 2021, 23, 5539-5544 \\ Read Online
}

ABSTRACT: A novel tandem Ru-catalyzed [2+2+2] cycloaddition of arylenynes to dihydrobiphenylenes followed by halogen-radical ring opening has been developed for the construction of tub-shaped halogenated benzocyclooctatetraenes (bCOT's). Cross-couplings and Diels-Alder reactions of the

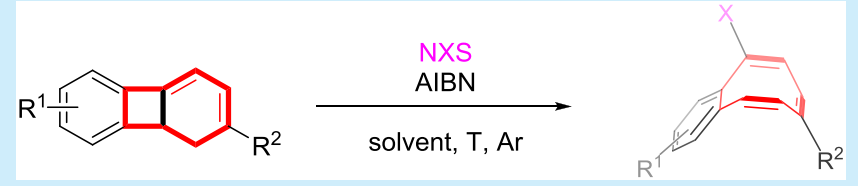
brominated bCOT's allow the formation of the corresponding eight-membered ring-fused PAH's. The halogen-radical ring opening probably occurs via a selective formation of a bis-allyl radical at the 1,3-cyclohexadiene moiety, halogenation at the bridgehead carbon, and finally electrocyclic ring opening.

$\mathrm{C}$ yclooctatetraenes (COT) are nonplanar tub-shaped hydrocarbon compounds having a $D_{2 d}$ conformation (more stable in its dynamic equilibrium than the planar $D_{4 h}$ and delocalized $D_{8 h}$ conformations) that have attracted a great deal of interest due to their electronic properties that result from having cyclic conjugated eight- $\pi$-electron systems. ${ }^{1}$ They are also very useful sterically demanding ligands for metals. ${ }^{2}$ These important features triggered an enormous effort throughout the years that aimed to develop and efficient synthesis of these archetypical medium-sized carbocycles ${ }^{3}$ with the aim of understanding their aromatic and antiaromatic properties according to Hückel's rules. ${ }^{4}$ More recently, nanographenes containing nonhexagonal rings are being considered as ideal models of defective graphene for building new semiconductor materials. ${ }^{5}$ In particular, distortion from planarity caused by the presence of eight-membered rings or the introduction of [8] circulene moieties that induce a deep curvature in the aromatic lattice and deeply influence the electronic and optical properties has attracted considerable attention. ${ }^{6}$ Consequently, the development of efficient synthetic methods for COT-embedded arenes is greatly significant and in high demand. In this context, synthetic approaches to dbCOT's, ${ }^{7}$ dbCOTP's, ${ }^{8}$ tribCOT's, ${ }^{9}$ and tetraphenylenes ${ }^{10}$ are relatively well studied while the simple benzocyclooctatetraenes (bCOT's) have received significantly less synthetic attention (Scheme 1). ${ }^{11}$ The parent benzocyclooctatetraene unit had also been observed in pioneer Günther's ${ }^{12}$ studies of Birch reduction of biphenylene in which the double protonation of the dianion occurred at the bridgehead position giving $4 \mathrm{a}, 8 \mathrm{~b}$-dihydrobiphenylene. ${ }^{13}$ This reactive species very rapidly evolved to the more stable benzocyclooctatetraene via thermal electrocyclic ring opening (Scheme 1).

On the contrary, a mild and powerful method for assembling 1,3-cyclohexadiene units (dihydrobiphenylene isomers) had been recently developed in our group via $\mathrm{Ru}(\mathrm{II})$-catalyzed
Scheme 1. COT-Embedded Polycyclic Arenes, Birch Reduction of Biphenylene, and Formation of Cyclooctatetraenes by Halogen-Radical Ring Opening of 1,8b-Dihydrobiphenylenes

(1) (Poly)benzofused cyclooctatetraenes

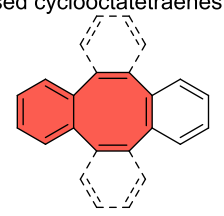

dbCOT, dbCOTP, tribCOT, tetraphenylene

(2) Günther's studies

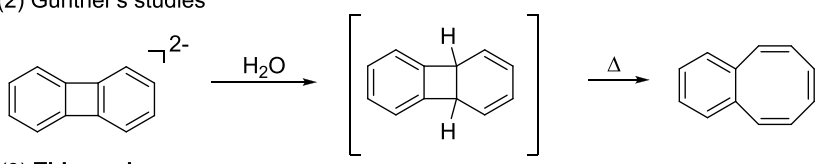

(3) This work

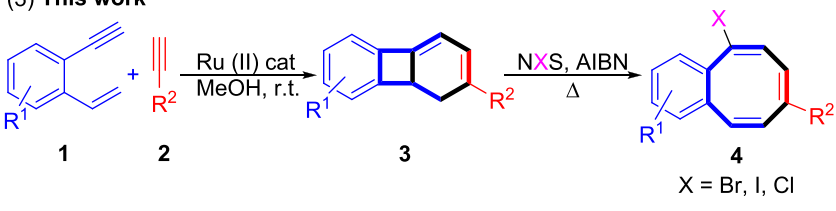

$[2+2+2]$ cycloaddition of arylenynes and alkynes. ${ }^{14}$ This type of cyclohexadiene has been utilized in efficient synthetic manipulations such as oxidations and Diels-Alder reactions. ${ }^{15}$ Moreover, a tandem Ru-catalyzed [2+2+2] cyclization/iodinemediated ring expansion of enediynes led to a straightforward

Received: June 7, 2021

Published: July 6, 2021 
assembly of benzo-fused bridged ketones. ${ }^{16}$ However, to the best our knowledge, the radical opening of benzo-fused cyclohexadienes has not been investigated even though such combined processes have synthetic potential for accessing interesting functionalized scaffolds. Herein, we report an efficient tandem process based on a Ru-catalyzed $[2+2+2]$ cycloaddition of arylenynes 1 with alkynes 2 to $1,8 \mathrm{~b}$ dihydrobiphenylenes $3^{14}$ followed by halogen-radical ring opening to benzocyclooctatetraenes 4 (Scheme 1). The halogenated (mainly, bromo derivatives) bCOT's have proved to be privileged functionalized structural units for accessing PAH's that combine aromatic and antiaromatic properties. ${ }^{17^{\circ}}$

Inspired by Günther's observations, we began our investigation by examining the well-known Wohl-Ziegler bromination $^{18}$ of dihydrobiphenylene $3 \mathrm{a}$. Thus, as a proof of concept, the use of NBS and AIBN as radical initiators in $\mathrm{CCl}_{4}$ at $\mathrm{rt}$ promoted the formation of the desired bromobenzocyclooctatetraene $\mathbf{4 a}$, although in low yield (Table 1 , entry 1 ).

Table 1. Optimization of Halogen-Radical Ring Opening of 1,8b-Dihydrobiphenylene $3 a$ to

Halobenzocyclooctatetraenes $4 \mathrm{a}(\mathrm{X}=\mathrm{Br}), 4 \mathrm{a}^{\prime}(\mathrm{X}=\mathrm{I})$, and $4 a^{\prime \prime}(\mathrm{X}=\mathrm{Cl})^{a}$

\begin{tabular}{|c|c|c|c|}
\hline & \multicolumn{2}{|c|}{$\begin{array}{c}\text { NXS ( } 1.1 \text { equiv) } \\
\text { AIBN ( } 0.11 \text { equiv) }\end{array}$} & $=$ \\
\hline entry & solvent & $T\left({ }^{\circ} \mathrm{C}\right)$ & yield of $4 a^{b}$ \\
\hline 1 & $\mathrm{CCl}_{4}$ & $\mathrm{rt}$ & 30 \\
\hline 2 & $\mathrm{CCl}_{4}$ & reflux & 85 \\
\hline 3 & DCM & reflux & 32 \\
\hline 4 & $\mathrm{CHCl}_{3}$ & reflux & 38 \\
\hline 5 & heptane & reflux & 44 \\
\hline 6 & $\mathrm{CH}_{3} \mathrm{CN}$ & reflux & 40 \\
\hline 7 & 1,4-dioxane & reflux & 61 \\
\hline 8 & $\mathrm{DCE}$ & reflux & 66 \\
\hline 9 & benzene & reflux & 65 \\
\hline 10 & $\mathrm{CCl}_{4}$ (darkness) & reflux & 53 \\
\hline 11 & $\mathrm{CCl}_{4}$ (no $\left.\mathrm{AIBN}\right)$ & reflux & 30 \\
\hline 12 & $\mathrm{CCl}_{4}$ (no NBS) & reflux & SM (50) \\
\hline $13^{c}$ & $\mathrm{CCl}_{4}$ & reflux & $77, \mathbf{4 a}^{\prime}$ \\
\hline $14^{d}$ & $\mathrm{CCl}_{4}$ & reflux & $36,4 a^{\prime \prime}$ \\
\hline
\end{tabular}

${ }^{a}$ Reaction conditions: $3 \mathbf{a}(0.2-0.3 \mathrm{mmol})$ in solvent $(0.036 \mathrm{M})$, NBS (1.1 equiv), AIBN (0.11 equiv), $1-1.5$ h. ${ }^{b}$ Isolated yield. ${ }^{c}$ NIS. ${ }^{d}$ NCS.

Gratifyingly, when the reaction temperature is increased at reflux, the yield of $\mathbf{4 a}$ increases to $89 \%$ (Table 1, entry 2). Other solvents were then tested. The use of chlorinated solvents like $\mathrm{CHCl}_{3}$ or $\mathrm{CH}_{2} \mathrm{Cl}_{2}$ or nonpolar heptane or polar $\mathrm{CH}_{3} \mathrm{CN}$ afforded $4 \mathrm{a}$ but in lower yields (Table 1, entries 3-6). By contrast, polar ethereal or aprotic solvents such as 1,4dioxane or DCE and a nonpolar solvent like benzene gave $\mathbf{4 a}$ in fairly good yields (Table 1, entries 7-9). Experimental reaction conditions using $\mathrm{CCl}_{4}$ as a solvent were then examined. Thus, performing the reaction in the absence of light led to a lower yield of $\mathbf{4 a}$ (Table 1, entry 10) as did not using AIBN as a radical initiator (Table 1, entry 11). In addition, the presence of NBS is mandatory for the consumption of starting product $3 \mathbf{a}$, while the rest gave rise to a complex mixture (Table 1, entry 12). ${ }^{19}$ The use of other halogen sources (NIS and NCS) is also feasible, affording the corresponding iodinated $\left(\mathbf{4} \mathbf{a}^{\prime}\right)$ and chlorinated (4a") benzocyclooctatetraenes albeit in lower yields (Table 1, entries 13 and 14).

With the optimized conditions in hand, we next investigated the scope of the reaction (Scheme 2). For dihydrobipheny-

Scheme 2. Radical Ring Opening of Dihydrobiphenylenes 3 to bCOT's $4^{a}$

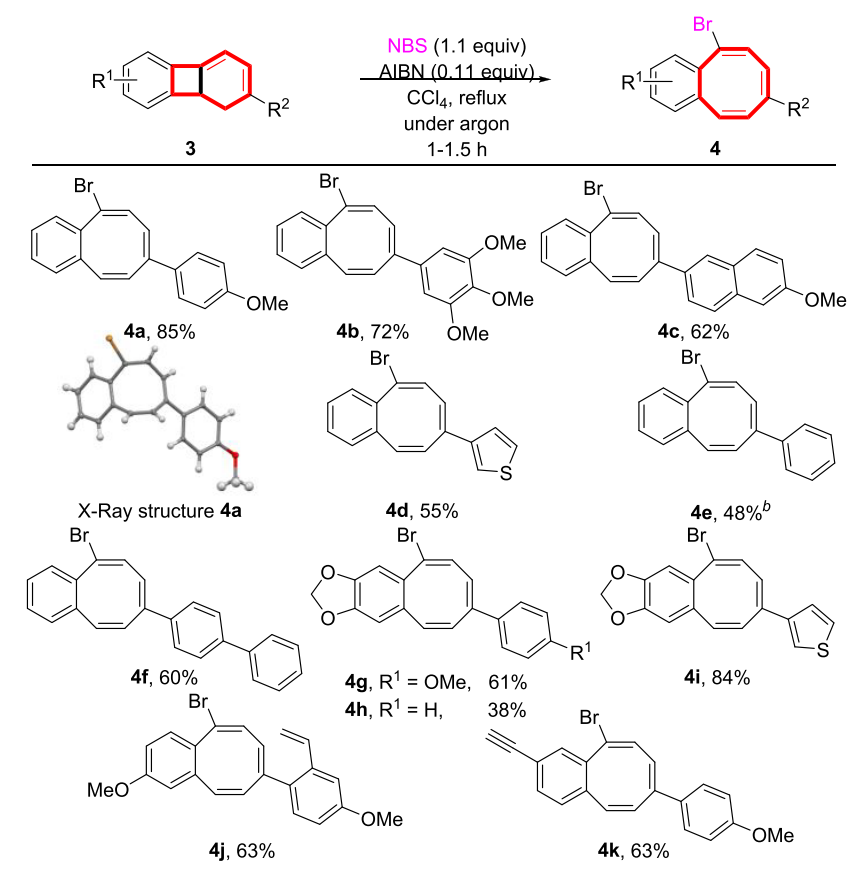

${ }^{a}$ Reaction conditions: $3(0.2-0.3 \mathrm{mmol})$ in $\mathrm{CCl}_{4}(0.036 \mathrm{M})$, NBS (1.1 equiv), AIBN ( 0.11 equiv), $1-1.5 \mathrm{~h}$. Isolated yield. The ORTEP drawing of 4 a shows ellipsoids at the $50 \%$ contour probability level.

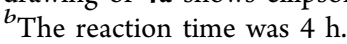

lenes $\mathbf{3}$ arising from electron-rich arylalkynes $\mathbf{2}$ and arylenyne 1a $\left(\mathrm{R}^{1}=\mathrm{H}\right)$, either the trialkoxyphenyl $3 \mathbf{b}$, the 6methoxynaphthyl 3c, or the heteroaryl 3-thiophene 3d behaves similarly giving fairly good yields of the corresponding bCOT's $\mathbf{4 b}-\mathbf{d}$. Not unexpectedly, the parent phenyl dihydrobiphenylene $3 \mathrm{e}$ affords the benzocyclooctatetraene $4 \mathrm{e}$ in a moderate yield $(48 \%)$, probably due to the lower electron richness of the influential aryl ring involved in the electrocyclic opening. ${ }^{20}$ Curiously, with an extended conjugated $\pi$-system, such as in dihydrobiphenylene $3 \mathbf{f}$, the ring opening was favorably affected giving rise to the biphenyl benzocyclooctatetraene $\mathbf{4 f}$ in a fairly good yield. On the contrary, dihydrobiphenylenes 3 arising from the electron-rich dialkoxy arylenyne $1 \mathbf{b}\left(\mathrm{R}^{1} / \mathrm{R}^{1}=\right.$ $\left.\mathrm{OCH}_{2} \mathrm{O}\right)$ and electron-rich alkynes 2 gave rise to the corresponding benzocyclooctatetraenes $4 \mathrm{~g}-\mathbf{i}$ in moderate to good yields, showing the versatility of combining one or two electron-rich partners. Interestingly, the vinyl substituent on dihydrobiphenylene $3 \mathbf{j}$, derived from $\mathrm{Ru}$-catalyzed dimerization of 1-ethynyl-4-methoxy-2-vinylbenzene $1 \mathbf{c})^{14}$ or the ethynyl substituent on $3 \mathbf{k}$ [from Ru-catalyzed cycloaddition of $\mathbf{1 d}\left(\mathrm{R}^{1}=\right.$ alkynyl $)$ and $\left.2 \mathrm{a}\right]$ remained intact under the radical conditions giving the corresponding styrenic bCOT $\mathbf{4 j}$ and acetylenic bCOT $\mathbf{4 k}$ in fairly good yields that might be capable of future manipulations. ${ }^{21}$ 
Interestingly, the heteroannulated benzocyclooctatetraenes $\mathbf{6 a}$ and $\mathbf{6 b}$ could be assembled in moderate yields via a one-pot, two-step process from arylenynes $\mathbf{5 a}$ and $\mathbf{5} \mathbf{b}$ bearing an $\mathrm{O}$ and a NTs group as linkers (Scheme 3, eq 1). ${ }^{16}$ Double tandem

Scheme 3. Heteroannulated bCOT's $6 a$ and $6 \mathrm{~b}$, Linear BenzodiCOT 9, and Scale-Up Synthesis of bCOT $4 a^{a}$

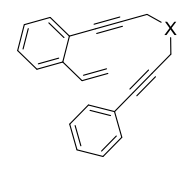

$$
\frac{\text { 1) }\left[\mathrm{Cp}^{*} \mathrm{Ru}\left(\mathrm{CH}_{3} \mathrm{CN}\right)_{3}\right] \mathrm{PF} F_{6}(10 \mathrm{~mol} \%)}{\mathrm{THF}, \mathrm{rt}}
$$

$5 \mathbf{a}, X=0$
$5 \mathbf{b}, X=N T s$
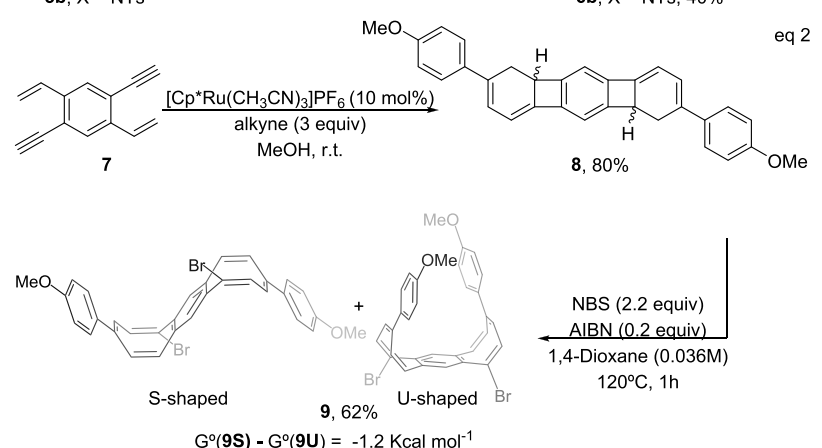

$\mathrm{G}^{\circ}(\mathbf{9 S})-\mathrm{G}^{\circ}(\mathbf{9 U})=-1.2 \mathrm{Kcal} \mathrm{mol}^{-1}$
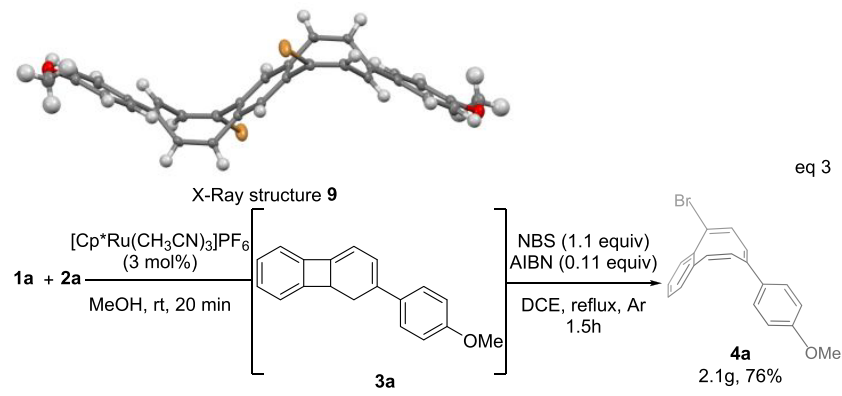

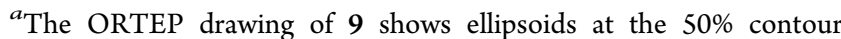
probability level.

processes were also accessible. Thus, a simple and straightforward entry to the linear benzodiCOT 9 (benzo[1,2:4,5] di[8]annulene), ${ }^{22}$ an appealing nonbenzenoid PAH structure with intriguing electronic and aromatic properties, ${ }^{23}$ was achieved from 1,4-diethynyl-2,5-divinylbenzene 7. The double $\mathrm{Ru}$ catalyzed $[2+2+2]$ cycloaddition of 7 with alkyne $\mathbf{2 a}$ led to the linear tetrahydro[3] phenylene 8 in an excellent $80 \%$ yield. The halogen-radical double ring opening of 8 with NBS in DCE occurred uneventfully to give the benzodiCOT 9 in a satisfactory $62 \%$ yield as a mixture of $U$ - and S-shaped conformers in solution, the S-shaped form being $1.2 \mathrm{kcal} \mathrm{mol}^{-1}$ more stable than the U-shaped form as shown by DFT calculations (Scheme 3, eq 2). ${ }^{24}{ }^{1} \mathrm{H}$ NMR spectra of 9 reveal the presence of the two conformers at rt in a 1:2.5 ratio, $U$ - and $S$-shaped, which could be thermally equilibrated to $1: 1.5$ ratio at $100{ }^{\circ} \mathrm{C}$. Single crystals of 9 suitable for X-ray diffraction analysis were grown from a solution in a hot $\mathrm{CHCl}_{3} /$ hexane mixture by slow evaporation of the solvents. 9 shows an Sshaped geometry with the bromine atoms on opposite faces with respect to the central benzene plane. In addition, the two eight-membered rings are considerably bent up and down from the plane of the central benzene unit with a large dihedral angle of $\sim 138^{\circ}$. Similar to COT, the two eight-membered rings adopt a tub-shaped conformation, with large bond length alternation. The bonds of the central six-membered rings are within the typical range of 1.39-1.40 $\AA$, revealing an aromatic benzenoid character. Scaling up was also feasible as shown by performing a tandem process from initial enyne $\mathbf{1 a}$ and arylalkyne $\mathbf{2 a}$ without the isolation of dihydrobiphenylene $\mathbf{3 a}$. Thus, reaction of $1 \mathrm{a}(8.1 \mathrm{mmol})$ and $2 \mathrm{a}(9.7 \mathrm{mmol})$ in $\mathrm{MeOH}$ under catalytic conditions (as little as $3 \% \mathrm{Ru}$ ) followed by a rapid replacement of the solvent with the apolar DCE to perform the radical reaction allowed us to obtain bCOT 4a $(2.1 \mathrm{~g})$ in a $76 \%$ overall yield (Scheme 3 , eq 3 ).

In an effort to gain further insights into the reaction mechanism, DFT calculations were performed to analyze all possible radical pathways. ${ }^{24}$ We began the mechanistic studies by elucidating the selectivity of the initial radical formation because two different radicals can be formed depending on the abstractions of the tertiary hydrogen $\mathrm{H}^{1}$ of the cyclobutene moiety or one of the two secondary hydrogens $\mathrm{H}^{2}$ on the 1,3cyclohexadiene core. Even though tertiary $\mathrm{C}-\mathrm{H}$ bonds are weaker than secondary ones, the presence of the cyclobutene moiety dramatically changes the reactivity of the 1,3-cyclohexadiene core, making the formation of the secondary bisallylic radical I $4.3 \mathrm{kcal} \mathrm{mol}^{-1}$ more favorable than that of the allylic benzylic tertiary radical (Scheme 4). Atomic spin

Scheme 4. Bond Dissociation Energies (BDE's) of $\mathbf{H}^{1}$ and $\mathrm{H}^{2}$

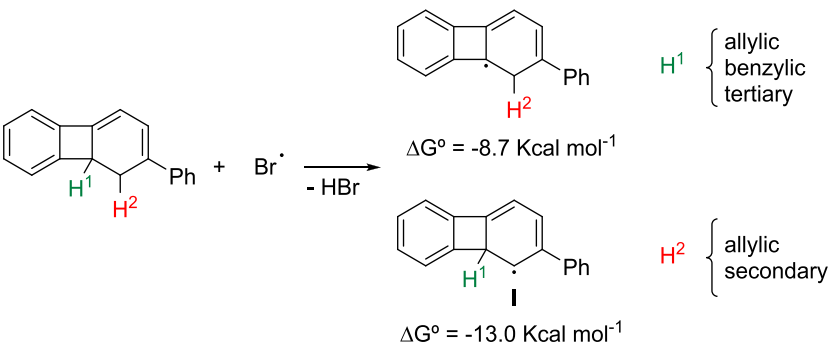

densities were then computed for the more stable allylic/ secondary radical I, showing that, as expected, it is mainly divided among the three carbons of the central six-membered ring. $^{24}$

We then evaluate the three possible evolution pathways for the most stable radical I (Figure 1): (a) six- $\pi$-electron electrocyclic ring opening followed by trapping of the resulting radical with $\mathrm{Br}_{2}$ to afford the observed cyclooctatetraene $4 \mathrm{e}$ $\left(\Delta G^{\ddagger}=39.2 \mathrm{kcal} \mathrm{mol}^{-1}\right.$, red pathway), (b) radical opening of the cyclobutane ring followed trapping with $\mathrm{Br}_{2}$ to afford terphenyl II ( $\Delta G^{\ddagger}=19.4 \mathrm{kcal} \mathrm{mol}^{-1}$, blue pathway), and (c) the most favorable one $\left(\Delta G^{\ddagger}=5.7 \mathrm{kcal} \mathrm{mol}^{-1}\right.$, black pathway) that involves direct bromination of the resonance structure of $\mathbf{I}$ with the radical into the tertiary, allylic, and benzylic position to give rise to the brominated dihydrobiphenylene III. Once III had been established as the most favorable product of radical bromination of $3 \mathbf{e}$, the observed product $4 \mathbf{e}$ would be formed through a six- $\pi$-electrocyclic ring opening. ${ }^{24}$

The utility of the brominated bCOT's 4 was tested in the preparation of valuable COT-embedded PAH's (Scheme 5). Suzuki cross-coupling between $\mathbf{4 a}$ and phenylboronic acid affords the expected phenyl-substituted bCOT 10 in $70 \%$ yield (Scheme 5, eq 1). Sonogashira couplings were also satisfactorily carried out under typical reaction conditions. Alkynyl-substituted COT's $1 \mathbf{1 a}$ and $\mathbf{1 1} \mathbf{b}$ were obtained in good to excellent yields using trimethylsilylacetylene 21 and 


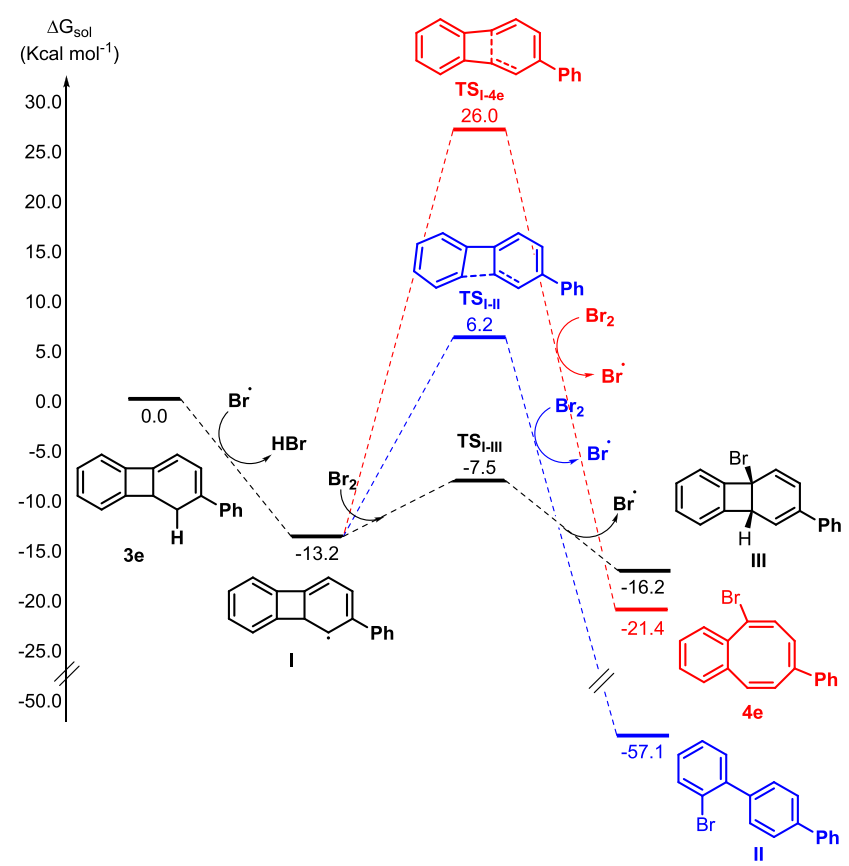

Figure 1. Free energy profiles for the radical bromination of $3 \mathbf{e}$. Energies are relative to $\mathbf{3 e}$ and are mass balanced.

Scheme 5. Synthetic Applications of Brominated bCOT's ${ }^{a}$
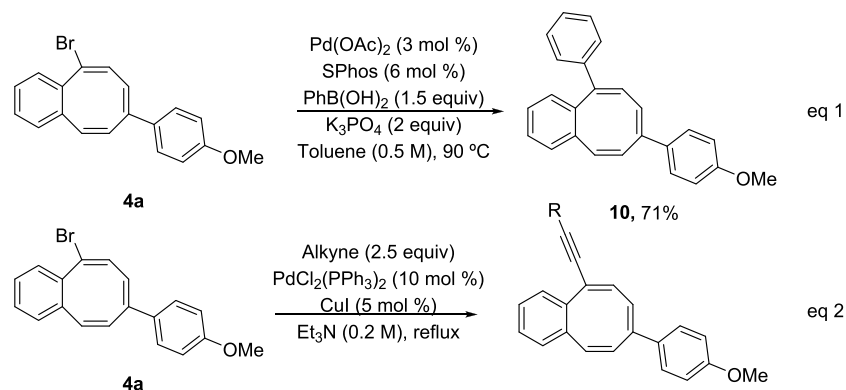

$4 a$

11b $\mathrm{R}=p-\mathrm{C}_{6} \mathrm{H}_{4} \mathrm{~N}\left(\mathrm{CH}_{3}\right)_{2}, 73 \%$ TBAF 11a R = TMS, $89 \%$

$-11 a^{\prime} R=H, 89 \%$
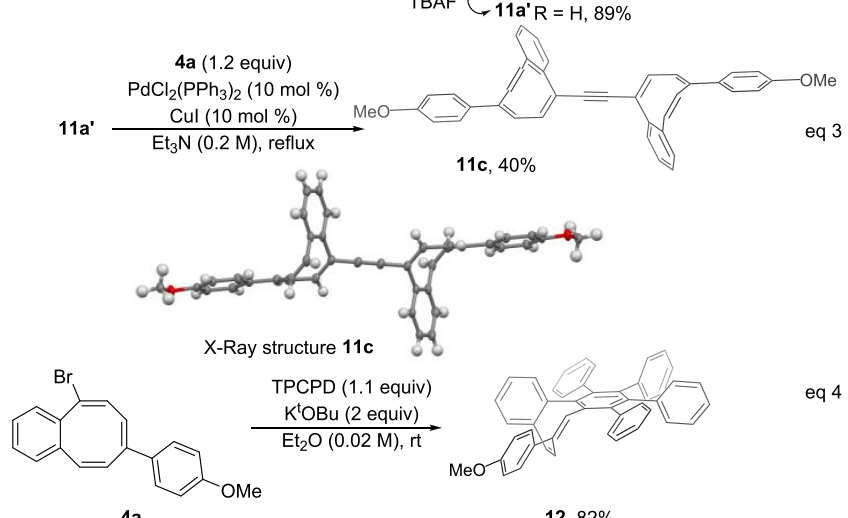

TPCPD (1.1 equiv)

$$
\frac{\mathrm{K}^{\mathrm{t} O B u}(2 \text { equiv })}{\mathrm{Et}_{2} \mathrm{O}(0.02 \mathrm{M}), \mathrm{rt}}
$$

4a

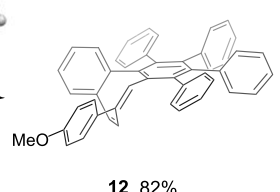

eq 4

${ }^{a}$ The ORTEP drawing of $11 \mathrm{c}$ shows ellipsoids at the $50 \%$ contour probability level.

alkynylaniline $\mathbf{2 m}$, respectively (Scheme 5 , eq 2 ). To our delight, an efficient Sonogashira coupling between $\mathbf{4 a}$ and alkynylCOT 11a' (from desilylation of 11a) renders uneventfully the interesting bis-COT derivative 11c, as confirmed by X-ray analysis (Scheme 5, eq 3). ${ }^{25}$ Finally, treatment of $4 \mathrm{a}$ with $\mathrm{KO}^{t} \mathrm{Bu}^{10}$ generates a strained cyclic alkyne that could be subsequently trapped as a dienophile with tetraphenylcyclopentadienone in a Diels-Alder reaction affording the $\pi$-extended dibenzoCOT 12 in very good yield (Scheme 5, eq 4). Note the higher reactivity of the triple bond in planarized systems containing one benzo-fused eightmembered ring ( $\mathrm{rt}, 25{ }^{\circ} \mathrm{C}$ ) as compared to the typical dibenzo-fused derivative $\left(\mathrm{Ph}_{2} \mathrm{O}\right.$ reflux, $\left.>250{ }^{\circ} \mathrm{C}\right) .^{26}$

In conclusion, we have developed a general synthetic method for constructing a new class of polycyclic arenes embedded with a brominated (halogenated) COT ring via a tandem $\mathrm{Ru}$-catalyzed $[2+2+2]$ cycloaddition of arylenynes to dihydrobiphenylenes followed by halogen-radical ring opening. The process involves the initial formation of a bis-allylic radical at the 1,3-cyclohexadiene core of the dihydrobiphenylene. Then, halogenation at the bridgehead position of the benzocyclobutene ring followed by a subsequent electrocyclic ring opening renders the observed cyclooctatetraene. This protocol provides a new synthetic approach to polycyclic arenes fused with an eight-membered ring (bCOT), which is expected to be applicable for the synthesis of diverse curved nanocarbons.

\section{ASSOCIATED CONTENT}

\section{Supporting Information}

The Supporting Information is available free of charge at https://pubs.acs.org/doi/10.1021/acs.orglett.1c01881.

General experimental procedures, X-ray crystallographic data, NMR spectra, and DFT calculations (PDF)

Computational details, free energy profile for the isomerization of benzodiCOT 9 from the U- to Sshaped conformers, complete free energy profile for the radical bromination of dihydrobiphenylene $3 \mathbf{e}$ and six- $\pi$ electron electrocyclic ring opening of brominated dihydrobiphenylene III, natural bond orbital analysis, references, and Cartesian coordinates, energy values, and imaginary frequencies for all of the stationary points involved throughout the DFT study (PDF)

\section{Accession Codes}

CCDC 2085992-2085994 contain the supplementary crystallographic data for this paper. These data can be obtained free of charge via www.ccdc.cam.ac.uk/data_request/cif, or by emailing data_request@ccdc.cam.ac.uk, or by contacting The Cambridge Crystallographic Data Centre, 12 Union Road, Cambridge CB2 1EZ, UK; fax: +44 1223336033.

\section{AUTHOR INFORMATION}

\section{Corresponding Author}

Carlos Saá - Centro Singular de Investigación en Química Biolóxica e Materiais Moleculares (CiQUS), Departamento de Química Orgánica, Universidade de Santiago de Compostela, 15782 Santiago de Compostela, Spain; (1) orcid.org/0000-0003-3213-4604; Email: carlos.saa@ usc.es

\section{Authors}

Jesús Bello-García - Centro Singular de Investigación en Química Biolóxica e Materiais Moleculares (CiQUS), Departamento de Química Orgánica, Universidade de Santiago de Compostela, 15782 Santiago de Compostela, Spain

Damián Padín - Centro Singular de Investigación en Química Biolóxica e Materiais Moleculares (CiQUS), Departamento 
de Química Orgánica, Universidade de Santiago de Compostela, 15782 Santiago de Compostela, Spain; (1) orcid.org/0000-0002-3841-727X

Jesús A. Varela - Centro Singular de Investigación en Química Biolóxica e Materiais Moleculares (CiQUS), Departamento de Química Orgánica, Universidade de Santiago de Compostela, 15782 Santiago de Compostela, Spain; (1) orcid.org/0000-0001-8499-4257

Complete contact information is available at: https://pubs.acs.org/10.1021/acs.orglett.1c01881

\section{Notes}

The authors declare no competing financial interest.

\section{ACKNOWLEDGMENTS}

This work has received financial support from MINECO (Project CTQ2017-87939R and ORFEO-CINQA Network RED2018-102387-T), the Xunta de Galicia (Project ED431C 2018/04 and Centro singular de investigación de Galicia accreditation 2019-2022, ED431G 2019/03), and the European Union (European Regional Development Fund). J.B.-G. thanks Xunta de Galicia for a predoctoral contract. The authors are also grateful to the CESGA (Xunta de Galicia) for computational time. Dedicated to Prof. K. Peter C. Vollhardt, Department of Chemistry, University of California, Berkeley, USA, on the occasion of his 75th birthday.

\section{REFERENCES}

(1) Nishinaga, T. Planar Cyclooctatetraenes and Related Ring Systems: Antiaromaticity and Applications. In Chemical Science of $\pi$ Electron Systems, 1st ed.; Akasaka, T., Osuka, A., Fukuzumi, S., Kandori, H., Aso, Y., Eds.; Springer: Tokyo, 2015; pp 47-67.

(2) For a review, see: Roesky, P. W. Substituted Cyclooctatetraenes as Ligands in f-Metal Chemistry. Eur. J. Inorg. Chem. 2001, 2001, $1653-1660$

(3) Wang, C.; Xi, Z. Metal mediated synthesis of substituted cyclooctatetraenes. Chem. Commun. 2007, 5119-5133.

(4) Baldridge, K. K.; Siegel, J. S. Quantum Mechanical Designs toward Planar Delocalized Cyclooctatetraene: A New Target for Synthesis. J. Am. Chem. Soc. 2001, 123, 1755-1759. See also ref 1.

(5) (a) Lu, P.; Hong, H.; Cai, G.; Djurovich, P.; Weber, W. P.; Thompson, M. E. Synthesis of Octasubstituted Cyclooctatetraenes and Their Use as Electron Transporters in Organic Light Emitting Diodes. J. Am. Chem. Soc. 2000, 122, 7480-7486. (b) Marquez, I. R.; Castro-Fernandez, S.; Millan, A.; Campana, A. G. Synthesis of distorted nanographenes containing seven- and eight-membered carbocycles. Chem. Commun. 2018, 54, 6705-6718.

(6) (a) Sakamoto, Y.; Suzuki, T. Tetrabenzo[8]circulene: Aromatic Saddles from Negatively Curved Graphene. J. Am. Chem. Soc. 2013, 135, 14074-14077. (b) Schlütter, F.; Nishiuchi, T.; Enkelmann, V.; Müllen, K. Octafunctionalized Biphenylenes: Molecular Precursors for Isomeric Graphene Nanostructures. Angew. Chem., Int. Ed. 2014, 53, 1538-1542. (c) Cheung, K. Y.; Chan, C. K.; Liu, Z.; Miao, Q. A Twisted Nanographene Consisting of 96 Carbon Atoms. Angew. Chem., Int. Ed. 2017, 56, 9003-9007. (d) Liu, M.; Liu, M.; She, L.; Zha, Z.; Pan, J.; Li, S.; Li, T.; He, Y.; Cai, Z.; Wang, J.; Zheng, Y.; Qiu, X.; Zhong, D. Graphene-like nanoribbons periodically embedded with four- and eight-membered rings. Nat. Commun. 2017, 8, 14924. (e) Pun, S. H.; Miao, Q. Toward Negatively Curved Carbons. Acc. Chem. Res. 2018, 51, 1630-1642. (f) Pun, S. H.; Wang, Y.; Chu, M.; Chan, C. K.; Li, Y.; Liu, Z.; Miao, Q. Synthesis, Structures, and Properties of Heptabenzo[7]circulene and Octabenzo[8]circulene. J. Am. Chem. Soc. 2019, 141, 9680-9686. (g) Urieta-Mora, J.; Krug, M.; Alex, W.; Perles, J.; Fernandez, I.; Molina-Ontoria, A.; Guldi, D. M.; Martin, N. Homo and Hetero Molecular 3D Nanographenes
Employing a Cyclooctatetraene Scaffold. J. Am. Chem. Soc. 2020, 142, 4162-4172. (h) Medel, M. A.; Tapia, R.; Blanco, V.; Miguel, D.; Morcillo, S. P.; Campaña, A. G. Octagon-Embedded Carbohelicene as a Chiral Motif for Circularly Polarized Luminescence Emission of Saddle-Helix Nanographenes. Angew. Chem., Int. Ed. 2021, 60, 60946100.

(7) (a) Man, Y. M.; Mak, T. C. W.; Wong, H. N. C. Arene synthesis by extrusion reaction. Part 14 . Synthesis of benzo-fused tetraphenylenes and crystal structure of a 4:1 clathrate inclusion compound of dibenzo $[\mathrm{b}, \mathrm{h}]$ tetraphenylene with p-xylene. J. Org. Chem. 1990, 55, 3214-3221. (b) Esser, B.; Bandyopadhyay, A.; Rominger, F.; Gleiter, R. From metacyclophanes to cyclacenes: synthesis and properties of [6.8]3 cyclacene. Chem. - Eur. J. 2009, 15, 3368-3379. (c) Nishiuchi, T.; Kuwatani, Y.; Nishinaga, T.; Iyoda, M. Dynamic Molecular Tweezers Composed of Dibenzocyclooctatetraene Units: Synthesis, Properties, and Thermochromism in Host-Guest Complexes. Chem. Eur. J. 2009, 15, 6838-6847. (d) Wender, P. A.; Lesser, A. B.; Sirois, L. E. Rhodium Dinaphthocyclooctatetraene Complexes: Synthesis, Characterization and Catalytic Activity in $[5+2]$ Cycloadditions. Angew. Chem., Int. Ed. 2012, 51, 2736-2740.

(8) (a) Wang, K. K.; Shi, C.; Petersen, J. L. A Facile Cascade Synthesis of 5,6-Diaryldibenzo[a,e]cyclooctenes from (Z,Z)-1-Aryl3,5-octadiene-1,7-diynes. J. Org. Chem. 1998, 63, 4413-4419. (b) Yang, L.; Matsuyama, H.; Zhang, S.; Terada, M.; Jin, T. Tandem Oxidative Ring Expansion for Synthesis of Dibenzocyclooctaphenanthrenes. Org. Lett. 2020, 22, 5121-5125.

(9) Wong, H. N. C. Synthesis of novel benzenoid molecules by lowvalent-titanium deoxygenation. Acc. Chem. Res. 1989, 22, 145-152.

(10) For a review, see: Han, J.-W.; Peng, X.-S.; Wong, H. N. C. Synthesis of tetraphenylene derivatives and their recent advances. Natl. Sci. Rev. 2017, 4, 892-916.

(11) (a) For early studies of bromination of biphenylenes to bromo derivatives of bCOT, see: Barton, J. W.; Henn, D. E.; McLaughlan, K. A.; McOmie, J. F. W. Biphenylenes. XII. The bromination of biphenylene. J. Chem. Soc. 1964, 1622-1625. (b) Barton, J. W.; Whitaker, K. E. Benzocyclooctatetraenes. Part I. Bromo derivatives formed in addition reactions of biphenylene. J. Chem. Soc. C 1968, 28-30. (c) Elix, J. A.; Sargent, M. V. Unsaturated eight-membered ring compounds. VI. Chemistry of benzocyclooctatetraene. J. Am. Chem. Soc. 1969, 91, 4734-4739. (d) Wong, H. N. C.; Sondheimer, F. 5,6,9,10-Tetradehydrobenzocyclooctene, the Simplest Known Planar Neutral Conjugated Eight-Membered Carbocycle. Angew. Chem., Int. Ed. Engl. 1976, 15, 117-118. (e) Kidokoro, H.; Sato, M.; Ebine, S. Re-examination on bromination of substituted biphenylenes. Formation of benzocyclooctatetraene derivatives. Chem. Lett. 1981, 10, 1269-1270. For a review, see: (f) Han, J.W.; Li, X.; Wong, H. N. C. Our Expedition in Eight-Membered Ring Compounds: From Planar Dehydrocyclooctenes to Tub-Shaped Chiral Tetraphenylenes. Chem. Rec. 2015, 15, 107-131.

(12) Günther, M.-E.; Aydin, R.; Buchmeier, W.; Engelen, B.; Güunther, H. Einfache Synthese von Benzocycloocten durch Protonierung von Biphenylen-Dianion. Chem. Ber. 1984, 117, 1069-1076.

(13) The dibromo derivative of this intermediate had been invoked as valence tautomer of the 3,8-dibromobenzoCOT. See also refs $11 \mathrm{c}$ and 11 e.

(14) García-Rubín, S.; González-Rodríguez, C.; García-Yebra, C.; Varela, J. A.; Esteruelas, M. A.; Saá, C. Dihydrobiphenylenes through Ruthenium-Catalyzed [2+2+2] Cycloadditions of ortho-Alkenylarylacetylenes with Alkynes. Angew. Chem., Int. Ed. 2014, 53, 18411844.

(15) (a) Jones, A. L.; Snyder, J. K. Synthesis of Unique Scaffolds via Diels-Alder Cycloadditions of Tetrasubstituted Cyclohexadienes. Org. Lett. 2010, 12, 1592-1595. (b) Shibuya, M.; Sudoh, T.; Kawamura, T.; Yamamoto, Y. A lactone-fused cyclohexadiene as a versatile platform for diversified synthesis of 5,6,5-tricyclic scaffolds. Org. Biomol. Chem. 2015, 13, 5862-5866.

(16) Yamamoto, Y.; Nishimura, K.-i.; Mori, S.; Shibuya, M. Assembly of a Benzo-Fused Bridged Ketone Scaffold from 1,5,10- 
Enediynes through One-Pot Ruthenium-Catalyzed Cyclization/ Iodine-Mediated Oxidative Ring Expansion. Angew. Chem., Int. Ed. 2017, 56, 5494-5497.

(17) For PAH-fused cyclooctatetraenes as fluorescent mechanochromic materials, see: Shohei, S.; Hiroshi, Y.; Hiroya, A. Preparation of polycyclic aromatic ring-fused cyclooctatetraene or oxepine compounds as fluorescent mechanochromic materials and polymeric compounds including them. WO 2019172200, 2019.

(18) Saikia, I.; Borah, A. J.; Phukan, P. Use of Bromine and BromoOrganic Compounds in Organic Synthesis. Chem. Rev. 2016, 116, 6837-7042.

(19) By contrast, reaction in the presence of $\mathrm{Br}_{2}$ gave a mixture of nonbrominated biphenylene (major) and $\mathbf{4 a}$ (minor) in a low combined yield.

(20) In fact, electron-poor aryls, e.g., $p-\mathrm{C}_{6} \mathrm{H}_{4} \mathrm{CF}_{3}$, failed to react.

(21) However, $\pi$-electron-rich conjugated vinyl dihydrobiphenylenes gave complex mixtures of products due, most likely, to the competence between electrophilic and radical mechanisms. See ref $11 \mathrm{e}$ and the Supporting Information for details.

(22) Elix, J. A.; Sargent, M. V.; Sondheimer, F. Unsaturated 8membered ring compounds. VII. Synthesis and cycloaddition reactions of 7,8-dimethylene-1,3,5-cyclooctatrienes. The synthesis of dicyclooctatetraeno[1,2:4,5] benzene. J. Am. Chem. Soc. 1970, 92, 962-968.

(23) (a) Paquette, L. A.; Ewing, G. D.; Traynor, S.; Gardlik, J. M. Dicyclooctatetraeno[1,2:4,5] benzene dianion and tetraanion. Experimental assessment of extended paratropic vs. restricted diatropic $\pi$ electron delocalization. J. Am. Chem. Soc. 1977, 99, 6115-6117. (b) Cohen, Y.; Klein, J.; Rabinovitz, M. The charge alternation concept. Application to cyclic conjugated doubly charged systems. $J$. Am. Chem. Soc. 1988, 110, 4634-4640. (c) El Bakouri, O.; Poater, J.; Feixas, F.; Solà, M. Exploring the validity of the Glidewell-Lloyd extension of Clar's $\pi$-sextet rule: assessment from polycyclic conjugated hydrocarbons. Theor. Chem. Acc. 2016, 135, 205. For a recent Scholl-based synthetic approach to a perylene-fused benzodiCOT derivative, see: (d) Zou, Y.; Han, Y.; Wu, S.; Hou, X.; Chow, C. H. E.; Wu, J. Scholl Reaction of Perylene-Based Polyphenylene Precursors under Different Conditions: Formation of Hexagon or Octagon? Angew. Chem., Int. Ed. 2021, DOI: 10.1002/ anie.202105427.

(24) See the Supporting Information for computational details.

(25) CCDC-2085994, 2085993, and 2085992 contain the supplementary crystallographic data for compounds $4 \mathrm{a}, \mathbf{9}$, and 11c, respectively. These data can be obtained free of charge from The Cambridge Crystallographic Data Centre via www.ccdc.cam.ac.uk/ data_request/cif.

(26) Huang, N. Z.; Sondheimer, F. The planar dehydro[8]annulenes. Acc. Chem. Res. 1982, 15, 96-102. 